\title{
Surface deformations from moderate-sized earthquakes in Mongolia observed by InSAR
}

\author{
Sh. Amarjargal ${ }^{1}$, T. Kato ${ }^{2}$, and M. Furuya ${ }^{3}$ \\ ${ }^{1}$ GPS Geodesy \& Geodynamics Group, Research Center for Astronomy and Geophysics, Ulaanbaatar, 15160, POB788, Mongolia \\ ${ }^{2}$ Earthquake Research Institute, The University of Tokyo, Yayoi 1-1-1, Bunkyo-ku, Tokyo 113-0032, Japan \\ ${ }^{3}$ Department of Natural History Sciences, Hokkaido University, N10W8, Kita-ku, Sapporo 060-0810, Japan
}

(Received August 11, 2009; Revised December 27, 2012; Accepted December 27, 2012; Online published August 23, 2013)

\begin{abstract}
We investigate surface deformations associated with two moderate-sized shallow earthquakes that occurred in the southeastern and northwestern stable regions of Mongolia using an analysis of ENVISAT/ASAR and ALOS/PALSAR data, respectively. Differential interferograms generated by a standard two-pass interferometric analysing technique depicted an uplift of up to $\sim 1 \mathrm{~cm}$ for the $M_{\mathrm{W}} 5.2$ Hatanbulag composite earthquake (20 July, 2005, moderate-size foreshock in three hours) and a subsidence of up to $\sim 10 \mathrm{~cm}$ for the $M_{\mathrm{W}} 5.1$ Büsiin Gol earthquake (19 January, 2008) in the radar line-of-sight directions, respectively. We inverted the observed deformations for the source parameters of the two earthquakes using elastic dislocation modeling. Our preferred model has geodetic moments of $\sim 3.83 \times 10^{17}\left(M_{\mathrm{w}} 5.6\right)$ and $5.56 \times 10^{16} \mathrm{~N} \mathrm{~m}\left(M_{\mathrm{w}} 5.1\right)$ for the Hatanbulag and Büsiin Gol earthquakes, respectively.
\end{abstract}

Key words: Co-seismic displacement, satellite geodesy, InSAR, Mongol earthquakes.

\section{Introduction}

During the past two decades, Interferometric Synthetic Aperture Radar (InSAR) has been shown to be a valuable tool for measuring surface deformations induced by earthquakes with an unprecedented spatial resolution at many different places on Earth. It has been successfully applied to observations of co-seismic (e.g., Zebker et al., 1994), post-seismic (e.g., Peltzer et al., 1998), and inter-seismic strain (e.g., Wright et al., 2001) associated with a number of large earthquakes. Moreover, its sensitivity to subtle displacements associated with moderate- to small-magnitude shallow earthquakes has been demonstrated; for example, at the $M 5.4$ (depth $2.6 \mathrm{~km}$ ) 1992 Landers aftershock (Feigl $e t$ al., 1995), the $M 4.7$ (depth $0.7 \mathrm{~km}), M 5.0$ (depth $3.5 \mathrm{~km}$ ), $M 5.3$ (depth $3.2 \mathrm{~km}$ ) and $M 5.4$ (depth $5.2 \mathrm{~km}$ ) earthquakes in the Zagros Mountains (Lohman and Simons, 2005), using C-band SAR data (wavelength $=5.6 \mathrm{~cm}$ ) and two shallow ( $\sim 1 \mathrm{~km}) M 4.7$ and $M 4.4$ earthquakes in Western Australia using L-band (wavelength $=23.6 \mathrm{~cm}$ ) and C-band SAR data, respectively (Dawson et al., 2008).

Here, we apply the InSAR technique to two shallow, moderate-sized earthquakes, that occurred in remote areas of Mongolia, to verify the InSAR detection capabilities in this kind of seismotectonic environment. Although Mongolia is considered to be a tectonically active region located in the transition zone between a N-S convergence to the south in the Tien Shan and a NW-SE extension to the north in the Baikal rift (Baljinnyam et al., 1993), it still remains the

Copyright (c) The Society of Geomagnetism and Earth, Planetary and Space Sciences (SGEPSS); The Seismological Society of Japan; The Volcanological Society of Japan; The Geodetic Society of Japan; The Japanese Society for Planetary Sciences; TERRAPUB.

doi:10.5047/eps.2012.12.015 least-studied and a poorly-understood region in northeast Asia because of the lack of seismic and geodetic observations. Since InSAR allows surface deformation measurements over vast areas without requiring any ground instrument deployment, it is a most suitable choice for employment in the current socio-economic conditions of Mongolia. From the ESA and JAXA datapool, we selected and processed interferometric pairs captured either by ENVISAT, Advanced Synthetic Aperture Radar (ASAR) or ALOS, Phased Array type L-type Synthetic Aperture Radar (PALSAR) over six small to moderate $(3.9 \leq M \leq 5.6)$ earthquakes that occurred in the territory of Mongolia. Of these, we failed to detect one due to the complete decorrelation of ASAR scenes in the densely-vegetated mountainous area (Büsiin Gol, $M_{\mathrm{w}}$ 5.4, 27 April 2005), and three were not detected, probably due to the deep depth, lack of data availability or location uncertainties in the seismic catalog, as we enconntered in the case of the Hatanbulag event, where the NSDC (National Seismological Data Center of Mongolia) cataloged location occurred outside the InSAR frame.

In the current work, we present an analysis of two earthquakes that were successfully detected by conventional interferometric processing using the available data. The first event occurred in Hatanbulag (composite, $M_{\mathrm{w}}$ 5.2, 20 July, 2005) in the southeastern Gobi (Fig. 1). The second, Büsiin Gol ( $M_{\mathrm{w}} 5.1$, 19 January, 2008) event, occurred in the Hövsgöl-Büsiin Gol rift (HBR) system in northwestern Mongolia (Fig. 2).

\section{Tectonic Background \\ 2.1 South East Gobi}

Hatanbulag is located in the southeastern Gobi region of Mongolia, that has long been considered as being his- 
torically aseismic and tectonically quiescent. This region and the most part of eastern Mongolia are covered by nonmarine basins formed during the late Mesozoic extension. The Mesozoic family of basins extend up to 1.5 million $\mathrm{km}^{2}$ from North China to the south and to the Amurian plain to the northeast. The northeast-trending East Gobi Basin (EGB) is one of these basins and together with the Züünbayan faults of the same trend represent the only two prominent geomorphological features of southeastern Gobi (Fig. 1). Various broad discussions characterize the EGB as an extensional and adjacent area which experienced contraction and extension in the late Mesozoic time (Zorin, 1999). Basement rocks of the EGB are generally upper Paleozoic flysch and volcanic arc sequences formed in a remnant ocean basin. The region is well known for abundant mineral resources (Oyu Tolgoi $\mathrm{Cu}-\mathrm{Au}-\mathrm{Mo}$ deposit, Dornogovi Ur deposit, Tavan Tolgoi coking coal deposit, oil fields in Tsagaan els and Züünbayan, etc.); however, tectonic models are still controversial. Rocks in southeastern Mongolia are considered to be a part of the Central Asian Orogenic Belt, or Altaids, and record history of the amalgamation of Asia via collision and accretion (Sengör et al., 1993). Therefore, data from this region are considered to have important implications for understanding the complex history of intracontinental deformation in Asia (Graham et al., 2001; Webb and Johnson, 2006). The Züünbayan and North Züünbayan faults, which are collectively referred to in some literature as the Züünbayan Fault Zone (ZBFZ) (Lamb et al., 1999), or the East Mongolian Fault Zone (EMFZ) (Yue and Liou, 1999), or the East Gobi Fault Zone (EGZF) (Webb and Johnson, 2006), follows the southern edge of the Altaid complex (Sengör et al., 1993) running along the EGB, and defines a structural corridor in this region. Yue and Liou (1999) and Lamb et al. (1999) proposed a kinematic linkage between the EGFZ and the Altyn Tagh fault through the Alxa fault, just south of the MongoliaChina border. Both define the EGFZ as a left-lateral strikeslip fault, but differ in the offset and the timing: $\sim 400 \mathrm{~km}$ offset in Cenozoic and $\sim 200 \mathrm{~km}$ offset mainly in Mesozoic, respectively. Evidence for middle-Cretaceous movement on faults within the EGFZ was identified using seismic reflection data by Johnson (2004). Outcrop data evidenced a sinistral strike-slip motion in the Cenozoic time (Webb and Johnson, 2006).

The 20 July, 2005, Hatanbulag (HB) earthquake occurred in the uplifted Hutag Uul cratonal block of Badarch et al. (2002) about $9.5 \mathrm{~km}$ southwest of Hatanbulag town, $\sim 50 \mathrm{~km}$ south of the Züünbayan fault and $\sim 30 \mathrm{~km}$ north of an unnamed fault (Fig. 1). The Hutag Uul block and Züünbayan fault separate the EGB to the south from its family basin Erlian in northern China. Two foreshocks preceded the mainshock on the same day at 18:06 and 20:02 UTC, the first of which had a magnitude of $M_{\mathrm{W}} 5.0$ according to the CMT and NEIC catalogs. In August 2011, one of us was able to visit the earthquake area. As local people reported, this earthquake was one of the strongest events they had ever felt in this area. During this event, the water of the Jirem well (about $2 \mathrm{~km}$ west from the epicenter, of about $2 \mathrm{~m}$ depth, Fig. 9), where local people collect their drinking water, disappeared. Owing to the sparse popula-

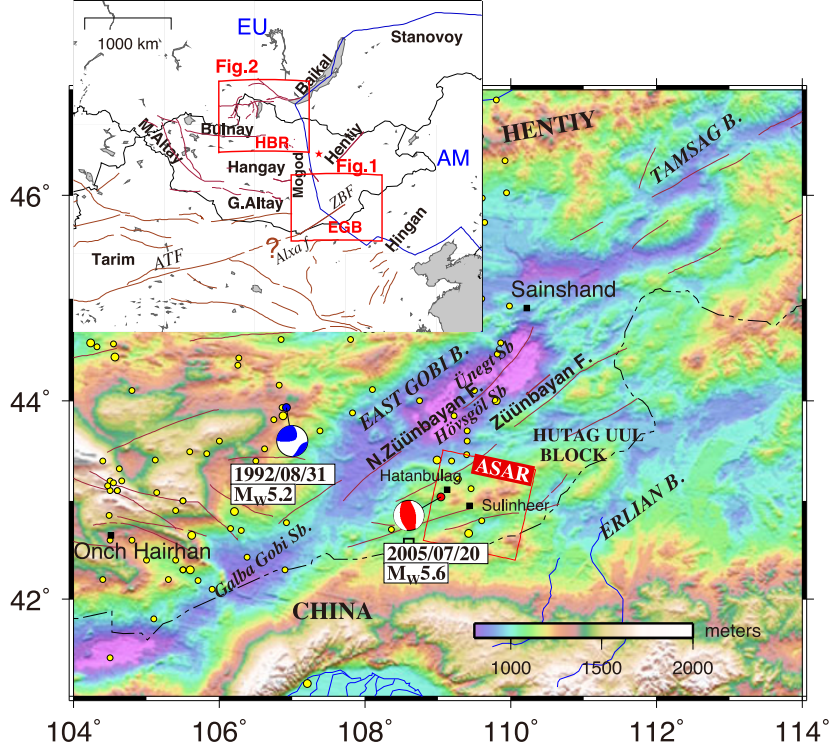

Fig. 1. Topography and major tectonic features of the region surrounding the 2005/07/20 Hatanbulag earthquake. Focal mechanisms are from the Global CMT catalog. Yellow dots show events with magnitudes $2 \leq M \leq 4.9$ that occurred since 1964 (earthquake location data for 1964-2006 from the NSDC Mongolia, 2006-2008 from NEIC). Faults are from the National Atlas of the Mongolian People's Republic. The red boxes in the inset map outline the area represented in Fig. 1 and Fig. 2.

tion, no significant damage was reported, except for some cracks that occurred in a wall of two buildings in the center of Hatanbulag town. Aftershocks rumbled during the following two days, and sounds and shaking were experienced in Sulinheer town, about $50 \mathrm{~km}$ southeast of Hatanbulag town (Fig. 3). There are records of a few small earthquakes $(2 \leq M \leq 4.9)$ within this region since 1964 (NSDC, National Seismological Data Center of Mongolia; Fig. 1). The closest recorded moderate-sized earthquake to the Hatanbulag event are the 1983 M 4.4 and 1998 M 4.7 earthquakes, which occurred over $40 \mathrm{~km}$ to the southeast and north, respectively, from the current event (Fig. 1).

\subsection{Hövsgöl-Büsiin Gol graben}

In contrast to the eastern part, the western and central parts of Mongolia are characterised by high seismic activities and have the main morphotectonic structures of the country. The Hövsgöl-Büsiin Gol Rift (HBR) system is the northernmost seismic zone of the country (Fig. 1) comprising three, almost parallel, NS-trending, small grabens (120$130 \mathrm{~km}$ long and 20-30 km wide): Büsiin Gol, Darkhad, and Hövsgöl, from right to left. These grabens are divided by strongly-faulted horst-type mountains and together with the eastern Sayan and EW-trending Tunka graben forms the southwestern flank of the Baikal rift system (Zonenshain and Savostin, 1981; Baljinnyam et al., 1993). The HBR is truncated in the south by the EW-trending Bulnay fault that was ruptured in the sequence of the $M_{\mathrm{s}} 8.2-8.3$ left-lateral strike-slip events of 1905. The Bulnay fault, together with parallel structures in the Sayan range to the north of the HBR, is considered to have caused the eastward motion of central Mongolia (Zonenshain and Savostin, 1981).

The HBR area is considered to lie at a junction where 


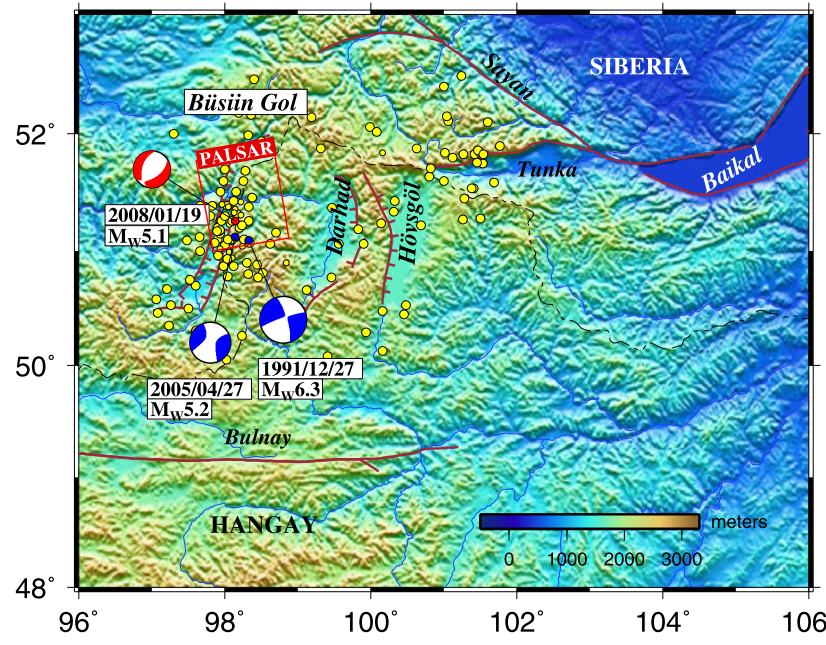

Fig. 2. Topography and major tectonic features of the region surrounding the 2009/01/19 Büsiin Gol earthquake. Focal mechanisms are from the Global CMT solutions: the red beachball shows the studied earthquake, the blue shows the two recent large events. Only earthquakes with $M \geq 4$ that occurred since 2003 are shown (from NSDC).

the compressional tectonics of western and central Mongolia meet the extensional deformation of the Baikal rift (Delouis et al., 2002; Logachev, 2003; Klyuchevskii et al., 2004). Locating the boundary between these two contrasting regimes has been the objective of the investigations of many authors. Obtaining an accurate estimate of the focal mechanism and slip model of the earthquakes is important for understanding the stress regime of the area, as well as for assessing the local seismic hazard.

Among the three grabens, the asymmetrical Büsiin Gol (BG) is distinguished by a deep, narrow structure and high seismicity. It is about $70 \mathrm{~km}$ long and $10-12 \mathrm{~km}$ wide. The floor of the graben lies at $1200 \mathrm{~m}$ and is occupied by the wide valley of the Büsiin Gol river and glacial deposits, covered by an impassable taiga, while the mountains of its eastern edge rise up to $3200 \mathrm{~m}$ and have inaccessible alp-like peaks (Uflyand et al., 1969). The edges of both sides of the graben are contoured by normal faults, which are considered to have been formed in the Devonian and Cambrian ages (Uflyand et al., 1969).

About 7000 small and moderate events have been recorded there since 1964 (NSDC). The major events were $M_{\mathrm{w}} 5.5$ (1 April 1976), $M_{\mathrm{w}} 6.5$ (27 December 1991) and $M_{\mathrm{w}} 5.4$ (27 April 2005). The focal mechanism solution of earthquakes in the BG area is a mixture of strike-slip and normal faulting with predominant strike-slip focal mechanism solution (Delouis et al., 2002; Fig.2). The 19 January, 2008, Büsiin Gol (BG) earthquake, discussed in this paper, occurred at the sharp eastern edge of the BG graben.

\section{InSAR Observations and Results \\ 3.1 Data and analysis}

The co-seismic deformation field of the Hatanbulag earthquake was observed using ASAR C-band data acquired from the descending tracks. From total twelve scenes observed from 13 January, 2004, to 02 January, 2007, in different seasons, seven are at pre-event, and five at post-event, times.
The investigation of the Büsiin Gol event was undertaken using eight PALSAR L-band data acquired from ascending tracks between 04 January, 2007, and 08 April, 2008. The PALSAR data set comprises both Fine Beam Single (FBS) and Fine Beam Dual (FBD) mode data mostly of the winter season. Two from the total of eight scenes are at a postevent time. Scene coverage for each radar is shown in the location maps of Fig. 1 and Fig. 2. The scenes from the ASAR and PALSAR data cover $100 \times 100 \mathrm{~km}$ and $70 \times 70$ $\mathrm{km}$ areas, respectively. Each of the datasets are well suited for applying to the landscapes of the corresponding study sites: the C-band data to the dry, sparsely-vegetated Hatanbulag area with a gently undulated terrain, and the longer wavelength L-band data to the densely-vegetated and highly rugged terrain of the Büsiin Gol area. Except for the deeper penetration capability to the dense vegetated area, the Lband data has a longer critical baseline of $13.1 \mathrm{~km}$ in the Fine Beam Single (FBS) mode and $6.5 \mathrm{~km}$ in the Fine Beam Dual (FBD) mode compared with the $1.1 \mathrm{~km}$ of the C-band ASAR data. The major disadvantage of L-band data is that the ionospheric effects are expected to be more than twenty times stronger than in the C-band. Also, due to the long wavelength, the sensitivity of the PALSAR to small deformations is limited, and the interpretation of single interferograms is complicated by the presence of atmospheric and topographic noise. In contrast to the ionosphere, the highlyvariable lower atmosphere has a similar effect on both frequencies and this remains a major limiting factor for any InSAR observations. Since both ASAR and PALSAR data sets have small off-nadir angles (23 and 38.7 degrees at the center of the scenes, respectively) they are mostly sensitive to vertical displacements.

We processed the data from raw format following the standard procedures of a two-pass approach (Massonet and Feigl, 1998) using the GAMMA software (Wegmüller and Werner, 1997). All images were aligned to one selected reference image, which allows the construction of any interferometric combination. The coregistration of images was performed with sub-pixel accuracy. To enhance the signalto-noise ratio (SNR), the ASAR interferograms were downsampled by a factor of ten and two in the azimuth and range directions, respectively, resulting in a $40 \mathrm{~m} \times 40 \mathrm{~m}$ ground pixel. The PALSAR interferograms were down-sampled by a factor of nine in the azimuth and three in the range directions, resulting in a $28 \mathrm{~m} \times 28 \mathrm{~m}$ ground pixel. In addition, we applied an adaptive power spectrum filter (Goldstein and Werner, 1998) to suppress the spatial noise in the interferograms. The removal of the topographic phase and the transformation from radar to geographic coordinates were carried out using a 3 arcsec digital elevation model (DEM) produced by the NASA Shuttle Radar Topography Mission (SRTM) (Farr et al., 2007). The ENVISAT satellite position was modelled using the precise orbit data (Scharroo and Visser, 1998) provided by the DEOS (Delft Institute for Earth-Oriented Space Research), while the ALOS satellite position was modelled with the precise orbit data supplied with the PALSAR metadata. Any residual orbital errors were further minimized through the removal of the planar trend surface from each interferogram. The baseline refinement was performed using the unwrapped phase and 
Table 1. ASAR and PALSAR Interferogram characteristics.

\begin{tabular}{lccrrr}
\hline inf & Date1 & Date2 & $\begin{array}{c}B_{\perp}, \\
(m)\end{array}$ & $\begin{array}{l}B_{\text {temp }}, \\
(\text { days })\end{array}$ & $\begin{array}{c}h_{a}, \\
(m)\end{array}$ \\
\hline \multicolumn{7}{c}{ ASAR (20 July, 2005, Hatanbulag) } \\
\hline hinf1 & $2005 / 02 / 01$ & $2006 / 02 / 21$ & -57 & 385 & -152 \\
hinf2 & $2004 / 01 / 13$ & $2007 / 01 / 02$ & 93 & 1084 & 92 \\
hinf3 & $2005 / 02 / 01$ & $2005 / 03 / 08$ & 344 & 37 & 25 \\
\hline \multicolumn{6}{c}{ PALSAR (19 January, 2008, Büsiin Gol) } \\
\hline binf1 & $2007 / 10 / 07$ & $2008 / 02 / 22$ & 1554 \\
binf2 & $2008 / 01 / 07$ & $2008 / 02 / 22$ & 877 & 138 & 33 \\
binf3 & $2007 / 10 / 07$ & $2008 / 04 / 08$ & 2120 & 184 & 24 \\
binf4 & $2008 / 01 / 07$ & $2008 / 04 / 08$ & 1443 & 92 & 35.7 \\
\hline
\end{tabular}

the same DEM. The phase unwrapping was undertaken using the Minimum Cost Flow (MCF) algorithm, where lowquality pixels are masked out, and the remaining data are triangulated and residues are identified. PALSAR data processing includes an additional step of oversampling of FBD data by a factor of two in the range direction before coregistration in order to transform them to the same pixel spacing as the FBS data.

\subsection{InSAR results}

3.2.1 Hatanbulag earthquake In general, the correlation of ASAR radar images was exceptionally good. Even our longest time-spanning interferogram (about 3 years between 2004 and 2007) shows a relatively high coherence except for small decorrelations in the NE-SW trending Harmagtain Gobi valley to the south of the scene and in the valley to the north of the scene (see Fig. 3). The scenes cover an almost flat terrain (100 m height differences) of dry bare ground with sparse vegetation and scattered small lakes and ponds, specific for desert basins. However, some of our scenes were obviously affected by atmospheric conditions such as precipitation, severe wind, or sand and dust storms that usually occur between February and May in this region. This is represented in some pre-seismic interferograms by the appearance of concentric fringes at the Halzan Dovny lake, the western margin of the deformation field (Fig. 3), and in the dried marshes and lakes of the Harmagtain Gobi valley, and by the significant contamination of the most promising co-seismic pairs in terms of temporal coverage. Our assumption has been confirmed by weather report data, provided by the Meteorology, Hydrology and Environment Monitoring Center (MHEMC) of Dornogovi province (N. Enkhmaa, Director of MHEMC, personal communication, 2011). In between, and at the date of, SAR image acquisitions in the period of February 2004 to September 2006, there were many days with emergency records of severe dust and snow, and rain storms with a speed of 14-20 $\mathrm{m} / \mathrm{s}$. It is not clear when the lakes and marshes became dry, but by the first visit to the earthquake area in the late August of 2011, we found only mud at the location of the Halzan Dovny lake, which probably is wetted from time to time only by precipitation. The concentric fringes in the pre-seismic interferograms can either be due to a thin layer of snow accumulation or soil swell at those locations, if the lakes were already dry at that time.

From all possible combinations of twelve ASAR scenes, we investigated twenty-nine interferograms with perpendic-

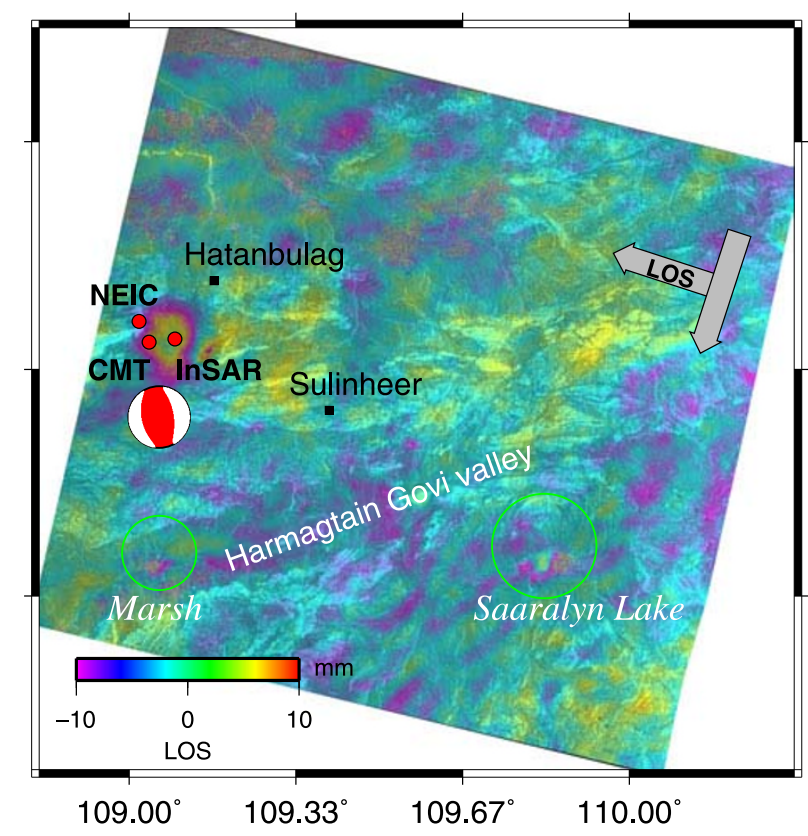

Fig. 3. Geocoded interferogram (scaled to yield displacement in units of mm of range change) spanning 385 days (hinf6). Positive LOS displacements are toward the satellite. The LOS direction is shown by the gray arrow. Red dots show seismic locations from the CMT and NEIC catalogs, and the InSAR solution. The more westerly NSDC location falls outside the map frame. The beachball represents the CMT solution.

ular baselines ranging from 2 to $482 \mathrm{~m}$, of which eleven contain pre-seismic, thirteen co-seismic, and five postseismic, information. We show in Table 1 only two independent co-seismic interferograms and one pre-seismic interferogram, which were selected for subsequent analysis.

All thirteen co-seismic interferograms, with different time spans and values of $h_{a}$ (the altitude variation producing a phase change of $2 \pi$ ), reveal a domal uplift of the surface with a maximum displacement of up to $\sim 10 \mathrm{~mm}$ in the line-of-sight (LOS) direction although many of them were contaminated. Among all co-seismic interferograms, the cleanest were those generated from pairs acquired nearly at the same season or month, such as 2005/02/01-2006/02/21 (hinfl, Fig. 3), 2005/03/08-2006/02/21 (not shown) and 2004/01/13-2007/01/02 (hinf2). The maximum LOS displacement on both hinfl and hinf2 is about $\sim 9 \mathrm{~mm}$. The deformation pattern, in general, is elliptical, with a minor 

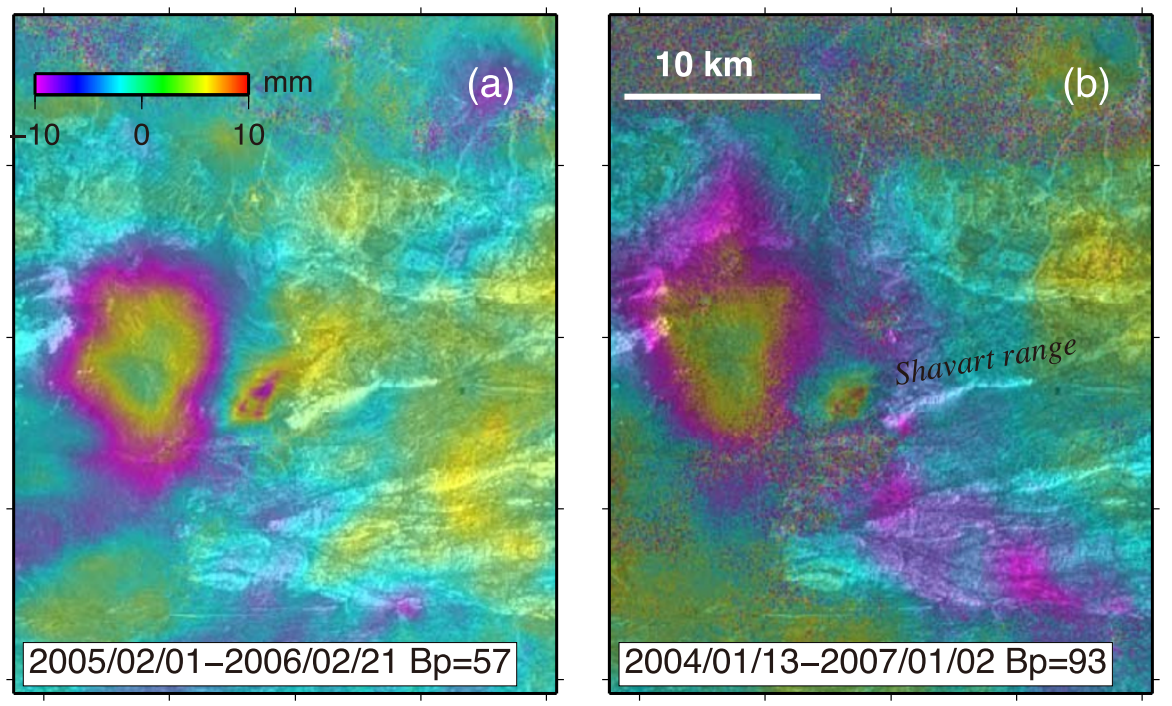

Fig. 4. Subset of observed co-seismic interferograms for the Hatanbulag earthquake: (a) hinfl and (b) hinf2. $B_{\perp}$ is the perpendicular baseline in meters.

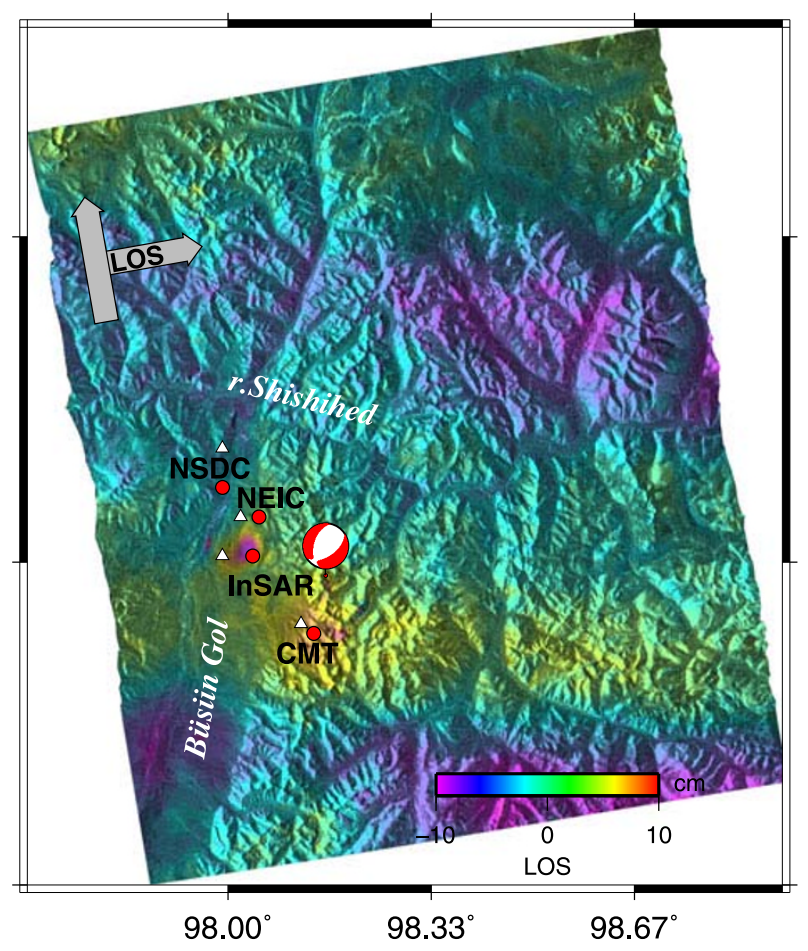

Fig. 5. Geocoded displacement map (unwrapped and scaled to $0.1 \mathrm{~m} /$ color-cycle) spanning 46 days and generated from the pair 2008/01/07-2008/02/22 (binf2). White triangles indicate the location of small to moderate shallow earthquakes recorded by co-seismic interferograms (see Table 4). Other notations are the same as for Fig. 3.

and major axis estimated to be approximately $\sim 8$ and 12 $\mathrm{km}$, respectively, stretching roughly NS. For the sake of space, we present only subsets of the two cleanest interferograms for the HB (Fig. 4(a), 4(b)) as well as for the BG (Fig. 6(a), 6(b)) earthquakes.

About $2.6 \mathrm{~km}$ to the east of this uplifted pattern, all coseismic interferograms also reveal a small area of displacements away from the radar, stretching $3 \mathrm{~km}$ in the NE-SW direction. Although the affected area here is small, the amplitude of the deformation signal is almost the same as for the uplifted area, reaching up to $-8 \mathrm{~mm}$. This deformation is observed with almost the same magnitude in three independent interferograms but is not visible in any pre-seismic interferograms. In order to reduce atmospheric noise, residual orbit error and, in addition, to ensure that the derived signal is actually related to surface deformation, we performed a stack of interferograms. The stacking of independent interferograms improves the ratio of the displacement signal to the atmospheric phase error by a factor of $\sqrt{ } N$, where $N$ is the number of interferograms (Strozzi et al., 2000). We stacked the co-seismic and pre-seismic interferograms separately, having excluded those scenes which have obvious atmospheric effects. The stacking produced cleaner interferograms with reduced noise levels, but preserved the NE-SW trending small negative signal. The stack of the pre-seismic interferograms did not display any distinct features at the event location, but, as previously noted, it revealed very clear concentric fringes at the small lake Halzan Dovny and the Jirem well, and in the marshes and lakes of the Harmagtain Gobi valley.

The negative NE-SW trending signal appears at the same location with the same shape after implementing three-pass differential interferometry using the "internal" DEM derived from the radar scenes. The shortest time-spanning pair 2005/02/01-2005/03/08 with a perpendicular baseline, $B_{\perp}=344 \mathrm{~m}$, was used as a topographic reference assuming there was no deformation during this period and the 2005/02/01-2006/02/21 pair (hinf6) was used as the pair containing the deformation signal. The results of the above test procedures leads to associate this questionable pattern with surface displacement, but not with atmospheric or topographic effects. The height of ambiguities of our interferograms are between $92 \mathrm{~m}$ and $152 \mathrm{~m}$, therefore the error in the SRTM DEM might lead to a phase error of up to $\frac{\sigma_{\text {DEM }}}{h_{a}}$ $=\frac{16 \mathrm{~m}}{152 \mathrm{~m}}$ or about 0.1 cycle. For ASAR acquisitions, this corresponds to $\sim 2.8 \mathrm{~mm}$.

3.2.2 Büsiin Gol earthquake Despite the rugged terrain with differences in elevation of more than $1000 \mathrm{~m}$, 

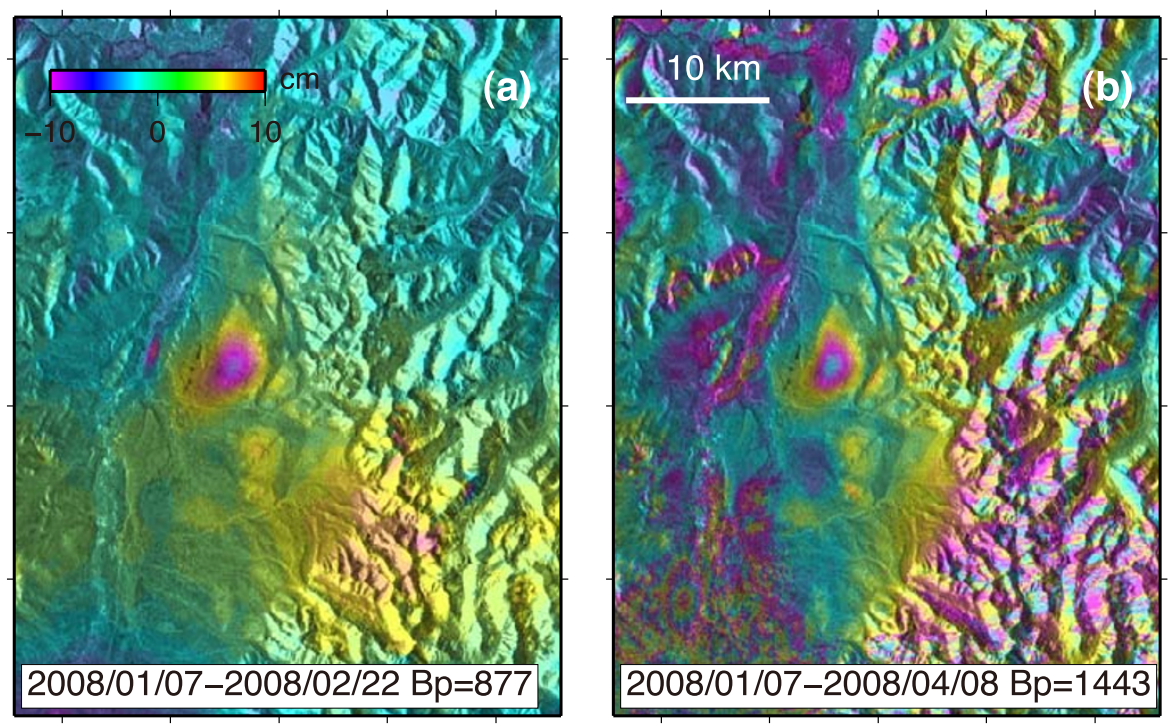

Fig. 6. Subset of observed co-seismic interferograms for the Büsiin Gol earthquake: a) binf2 and b) binf4.

and the dense larch forest cover, the L-band interferograms showed a high coherence (see Fig. 6(a)), enabling successful phase unwrapping for the entire scene, in contrast to the interferograms produced from the C-Band ASAR data in our attempt on the $M_{\mathrm{w}} 5.4$ earthquake (27 April, 2005) about $30 \mathrm{~km}$ south of the currently studied event (blue beachball in Fig. 2), as noted in the Introduction section of this paper. To compare with the Hatanbulag earthquake, for the 19 January, 2008, Büsiin Gol earthquake we had a limited number of acquisitions, among which there are only two post-seismic data. In addition, most of our interferograms were contaminated by heterogeneous atmospheric propagation, snow cover or layover, and foreshortening effects. We were able to construct four co-seismic interferograms using three FBS and one FBD PALSAR images acquired between October 2007 and April 2008. Two interferograms binf 2 and binf4 have the highest percentage of coherent area (100 to $95 \%$ ) while binfl and binf3 were coherent partly due to the temporal decorrelation. The binf 2 pair has the shortest time span of 46 days and a somewhat small perpendicular baseline of $B_{\perp}=877 \mathrm{~m}$, though the interferogram contains an anomalous effect, which is seen in a broad area extending latitudinally across the scene, to the south of the epicentral location, in spite of the planar trend surface removal (Fig. 5). This broad signal might be attributed to an orbital error, or tropospheric and ionospheric variations; however, it did not appear in any other interferograms that share either images that form binf2 (2008/01/07 and 2008/02/22).

Nevertheless, all of the above-discussed interferograms revealed an elliptical deformation pattern with similar dimensions and orientation near the epicenter of the 19 January, 2008, earthquake (Fig. 6). The deformation pattern elongates in the NE-SW direction and corresponds to $\sim 90 \mathrm{~mm}$ negative displacement (ground subsidence) in the LOS direction. The cleanest deformation signal was observed on two interferograms generated from the pairs 2008/01/07-2008/02/22 (binf2) and 2008/01/072008/04/08 (binf4, Fig. 6). On these two interferograms, the major and minor axes of the deformation field reach 6 and $4 \mathrm{~km}$, respectively, and the amplitude of the displacements in the LOS direction were 80 and $110 \mathrm{~mm}$, respectively. However, we have to consider also the topographic errors which are potentially important for this region of high elevation and rugged topography coupled with the relatively long perpendicular baseline of ALOS. If we assume that the SRTM DEM accuracy does not exceed the given theoretical value then the topographic contribution to the measured LOS displacement is about $1 / 4$ cycle or $30 \mathrm{~mm}$, calculated from the highest $h_{a}$ value of the binf 2 , or almost $38 \%$ of the observed average LOS displacement of $80 \mathrm{~mm}$.

\section{Modeling Results}

To explain the observed deformation pattern, we performed both forward and inverse modeling. We represent faults as rectangular dislocations with either a uniform or distributed slip, embedded in a homogeneous, isotropic, elastic half-space (Okada, 1985). We started with a series of forward modeling (Feigl and Dupré, 1999) using the CMT solutions as a priori data, constrained with the observed lobe shape and narrow fringe gradient. We estimated the longitude, latitude, depth $z$, dip $\delta$, strike $\alpha$, strike-slip, dipslip and dimensions of the best-fitting fault plane. In the inverse modeling, we optimized the fault geometry and attempted to derive the slip distribution using a non-negative least-squares approach with a smoothing constraint on the slip distribution. The inverse solution simultaneously minimizes the L-2 norm of the data misfit and the model roughness:

$$
\min \left[\|\mathbf{G m}-\mathbf{d}\|_{2}+\varepsilon^{-2}\|\mathbf{L m}\|_{2}\right],
$$

where the first term $\|\mathbf{G m}-\mathbf{d}\|_{2}$ is the L-2 norm of the data misfit and the second term $\varepsilon^{-2}\|\mathbf{L} \mathbf{m}\|_{2}$ is a measure of the model roughness. $\mathbf{G}$ is the Green's function, which describes how slip on a fault produces displacement at the surface, $\mathbf{d}$ is the observed displacement, $\mathbf{L}$ is the discrete Laplacian operator and $\mathbf{m}$ is a vector of model parameters. Inclusion of Laplacian smoothing in this solution 
avoids a sharp transition of slip between patches, while nonnegativity constraints prevents the sign of the fault patches from changing. For this step, we reduced the volume of the InSAR data to a more manageable size by subsampling from $10^{6}$ data points to $10^{3}$. Since the deformation data are highly correlated spatially, such a reduction does not lead to losing significant information. First, we subsampled interferograms by a factor of six along both the range and azimuth directions. Then the subimages were cropped to the region of interest. For the modeling, we used the average of the two cleanest independent interferograms, hinfl and hinf 2 , for the Hatanbulag earthquake, and binf 2 and binf3 for the Büsiin Gol earthquake. The data were downsampled using a quadtree partitioning algorithm (Jónsson et al., 2002) with a threshold value of $2.5 \mathrm{~mm}$ for the Hatanbulag interferograms and $2 \mathrm{~cm}$ for the Büsiin Gol interferograms because of the small magnitude of the earthquakes. In the quadtree algorithm, the scene is divided into four quadrants and the mean of each quadrant is calculated. If the rms scatter about the mean exceeds a given threshold, the quadrant is subdivided into four new quadrants and the mean is calculated, and compared with the data. The process continues iteratively until convergence. The observed, and quadtree decomposed, interferograms for both earthquakes are shown in Figs. 7 and 8.

Based on the obtained best fit fault parameters, we calculated the seismic moment $M_{0}=\mu L W U$ (Aki, 1972) and the moment magnitude $M_{\mathrm{w}}=\left(\log _{10} M_{0}-9.11\right) / 1.5$ (Hanks and Kanamori, 1979) from the fault length $L$, width $W$, the displacement $U$, and by assuming a rock rigidity $\mu=30 \mathrm{GPa}$.

\subsection{Hatanbulag earthquake}

The deformation for the Hatanbulag earthquake was found to cover a large area of about $8 \times 12 \mathrm{~km}^{2}$ but with a peak-to-peak magnitude of only $8-10 \mathrm{~mm}$. This small displacement was revealed despite the likely presence of water bodies (or snow wreath in some lake and marshes after the snow/dust storm) and sand dune drift in the small depression, where the epicenter is located. We obtained solutions for two cases with, and without, the questionable subsiding pattern to the east. The model that includes the eastern subsidence revealed a strike-slip mechanism with a fault plane size of $1.8 \times 1.3 \mathrm{~km}^{2}$ at a depth of $6.3 \mathrm{~km}$ and $1.3 \mathrm{~m}$ of slip. However, the modeled pattern did not match well the observed displacement, and the type of faulting is not consistent with the focal mechanism estimated previously from seismograms.

The model without the eastern subsidence revealed a thrust type mechanism with a small left-lateral component and best fits to the observations and the CMT and NEIC fault orientations. The preferred model has a nodal plane that strikes $352^{\circ}$ with $0.2 \mathrm{~m}$ of strike-slip, dips $49^{\circ} \mathrm{NW}$ with $0.42 \mathrm{~m}$ of dip-slip motion, and has a rake of $64^{\circ}$ (Table 3 ). The best compromise between seismic moment and depth was found for a plane that lies at a depth of $8.3 \mathrm{~km}$ with a geodetic moment of $M_{0}=3.83 \times 10^{17} \mathrm{~N} \mathrm{~m}\left(M_{\mathrm{w}} 5.65\right)$. Observed, modeled and residual interferograms (calculated by subtracting model displacements from that observed) are shown in Fig. 7. The residual interferogram exhibits a major misfit of about $2 \mathrm{~mm}$ at the southeastern end of the
Table 2. Source parameters of the Hatanbulag earthquake from seismology.

\begin{tabular}{|c|c|c|c|}
\hline Parameters & CMT & NEIC & NSDC \\
\hline & \multicolumn{3}{|c|}{ mainshock at 21:54 UTC } \\
\hline Longitude $\left({ }^{\circ}\right)$ & 109.04 & 109.02 & 108.71 \\
\hline Latitude $\left(^{\circ}\right)$ & 43.04 & 43.07 & 42.97 \\
\hline $\operatorname{Depth}^{\mathrm{a}}(\mathrm{km})$ & 12 & 6 & 2 \\
\hline Strike $\left(^{\circ}\right)$ & $166 / 352$ & $171 / 303$ & - \\
\hline $\operatorname{Dip}\left(^{\circ}\right)$ & $41 / 49$ & $49 / 53$ & - \\
\hline Rake $\left(^{\circ}\right)$ & $86 / 94$ & $127 / 56$ & - \\
\hline$M_{\mathrm{w}}$ & 5.2 & 5.2 & $M_{\mathrm{L}} 5.69$ \\
\hline \multirow[t]{2}{*}{$M_{0}(\mathrm{~N} \mathrm{~m})$} & $7.36 \times 10^{16}$ & $9.1 \times 10^{16}$ & - \\
\hline & \multicolumn{3}{|c|}{ foreshock at 18:06 UTC } \\
\hline Longitude $\left(^{\circ}\right)$ & 109.06 & 109.26 & 108.98 \\
\hline Latitude $\left(^{\circ}\right)$ & 43.01 & 43.045 & 43.12 \\
\hline $\operatorname{Depth}^{\mathrm{a}}(\mathrm{km})$ & 12 & 17 & 15 \\
\hline Strike $\left(^{\circ}\right)$ & $13 / 150$ & - & - \\
\hline $\operatorname{Dip}\left(^{\circ}\right)$ & $41 / 58$ & - & - \\
\hline Rake $\left(^{\circ}\right)$ & $125 / 64$ & - & - \\
\hline$M_{\mathrm{w}}$ & 5.0 & 5.0 & $M_{\mathrm{L}} 3.5$ \\
\hline$M_{0}(\mathrm{~N} \mathrm{~m})$ & $4.53 \times 10^{16}$ & - & - \\
\hline
\end{tabular}

deformation field, corresponding to the unmodelled subsidence, which we attributed to a local non-tectonic event (Fig. 7). The rms error for this model is $2.3 \mathrm{~mm}$. The position and orientation of the fault plane agree well with the NW-dipping nodal plane of the Global CMT and NEIC solutions. The rake is consistent with the NEIC estimation but differs by $30^{\circ}$ from those of the CMT. The geodetic moment is five and four times greater than the seismic moments of the CMT and NEIC solutions, respectively (Table 2).

\subsection{Büsiin Gol earthquake}

The deformation associated with the Büsiin Gol earthquake covered a smaller area of $6 \times 4 \mathrm{~km}^{2}$, but had a higher peak-to-peak magnitude of $8-10 \mathrm{~cm}$, typical for shallow depth events. The preferred best fitting fault model is estimated to be about $1.8 \mathrm{~km}$ long along strike and extends to a depth of $2.4 \mathrm{~km}$. It strikes N52 $2^{\circ}$ with $0.3 \mathrm{~m}$ of strike-slip and dips $49^{\circ} \mathrm{NW}$ with $0.57 \mathrm{~m}$ of dip-slip motion (Table 5). The InSAR estimated location for this earthquake is in good agreement with all three seismic solutions with the closest proximity to the NEIC estimation ( $4.4 \mathrm{~km}$ difference) while the CMT and NSDC place it about $11 \mathrm{~km}$ southeast and $8 \mathrm{~km}$ northwest, respectively. We note that the location uncertainty of the NSDC estimation for this event is relatively low compared with that for the $\mathrm{HB}$ event, presumably owing to the inclusion of the Russian Altay-Sayan network north of the $\mathrm{BG}$ event in the seismic processing (Dugarmaa et al., 2006; Klyuchevskii et al., 2007). The strike, dip and rake estimated, based on InSAR data, agree within $\sim 3^{\circ}$ with those of the CMT solution. The residual between the observed and modeled data is no more than 1 cm (Fig. 8), which is within the magnitude of the data errors. The rms error for this model is $2.4 \mathrm{~cm}$. The moment is $5.56 \times 10^{16}\left(M_{\mathrm{w}} 5.1\right)$, slightly larger than the CMT estimate of $4.91 \times 10^{16}$ (Table 4 ). 

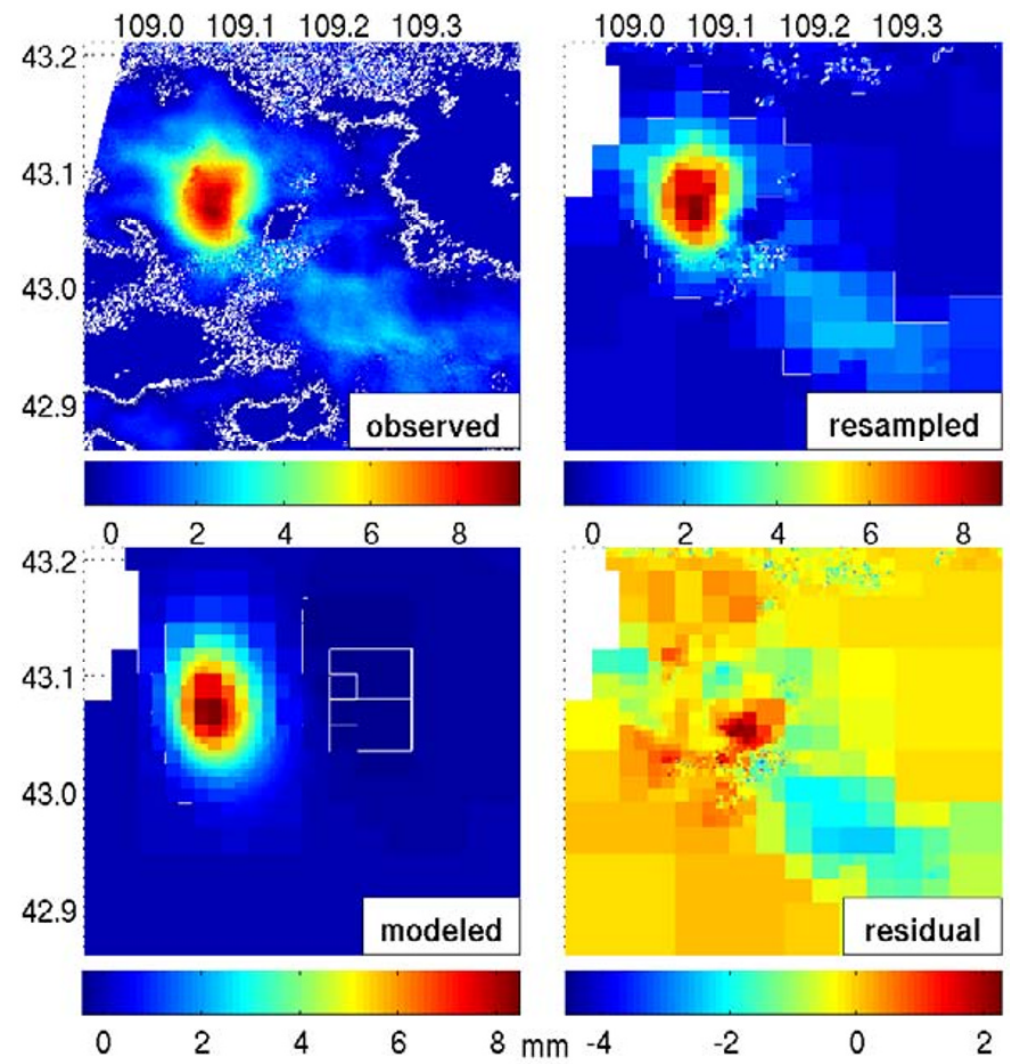

Fig. 7. Inversion results for the Hatanbulag earthquake. The observed (average of two independent interferograms) and resampled data are shown in the top panels, and the modeled and residual interferograms are shown in the bottom panels with the color bar indicating LOS deformation in $\mathrm{mm}$.
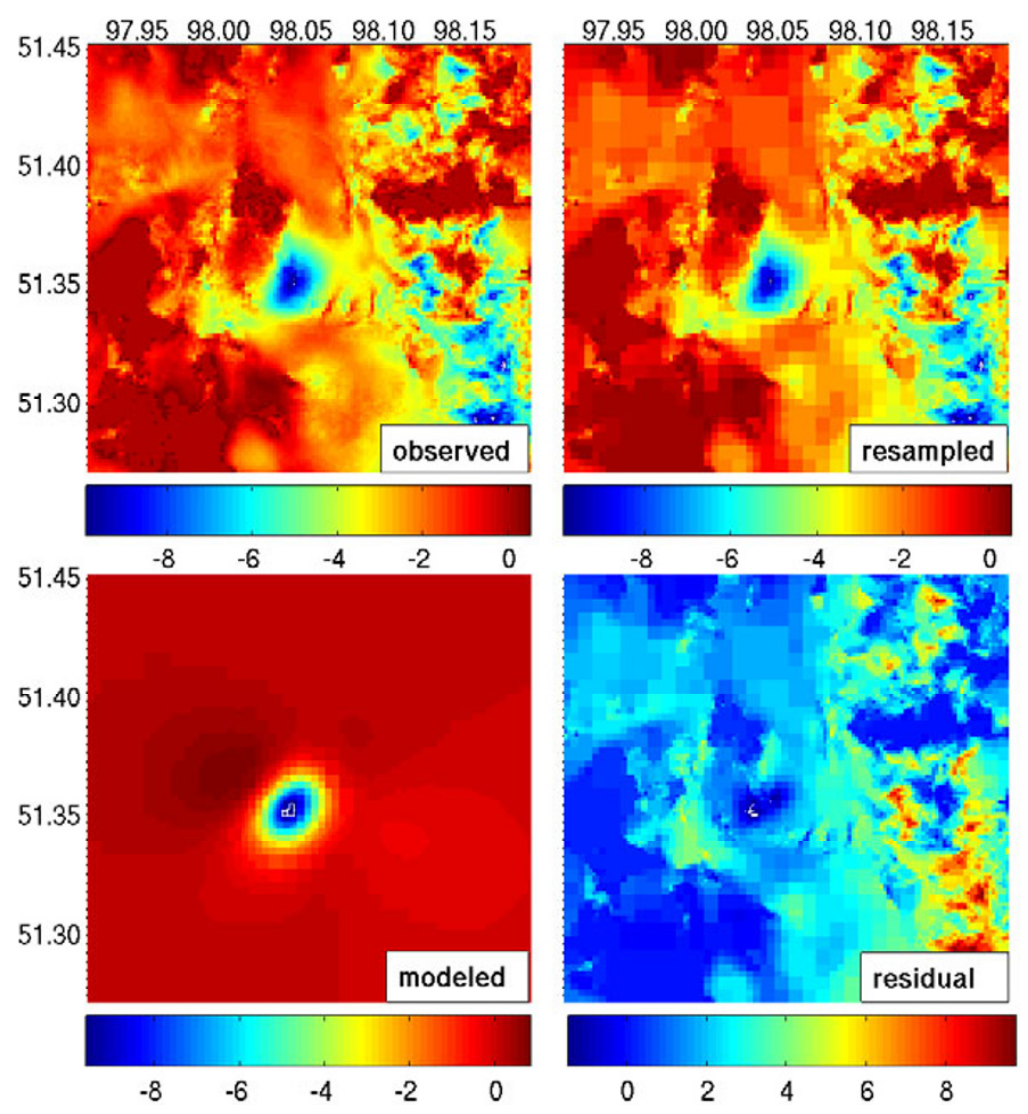

Fig. 8. Inversion results for the Büsiin Gol earthquake. The observed and resampled data are shown in the top panels, and the modeled and residual interferograms are in the bottom panels with the color bar indicating LOS deformation in $\mathrm{cm}$. 
Table 3. Earthquake source parameters of the Hatanbulag earthquake from InSAR estimates. ${ }^{\text {a }}$ The location and depth refer to the bottom left of the fault rectangle, following the convention of Okada (1985).

\begin{tabular}{|c|c|c|c|c|c|c|c|c|c|c|}
\hline $\begin{array}{c}\text { Longitude } \\
\left({ }^{\circ}\right)\end{array}$ & $\begin{array}{c}\text { Latitude } \\
\left({ }^{\circ}\right)\end{array}$ & $\begin{array}{c}\text { Depth }^{\mathrm{a}} \\
(\mathrm{km})\end{array}$ & $\begin{array}{c}\text { Strike } \\
\left({ }^{\circ}\right)\end{array}$ & $\begin{array}{l}\text { Dip } \\
\left({ }^{\circ}\right)\end{array}$ & $\begin{array}{c}\text { Rake } \\
\left({ }^{\circ}\right)\end{array}$ & $\begin{array}{c}\text { Length } \\
(\mathrm{km})\end{array}$ & $\begin{array}{l}\text { Width } \\
(\mathrm{km})\end{array}$ & $\begin{array}{l}\text { Slip } \\
(\mathrm{mm})\end{array}$ & $\begin{array}{l}\text { Moment } \\
(\mathrm{N} \mathrm{m})\end{array}$ & $M_{\mathrm{w}}$ \\
\hline 109.092 & 43.045 & 8.3 & 352 & 49 & 64 & 5 & 5.5 & 465 & $3.83 \times 10^{17}$ & 5.65 \\
\hline
\end{tabular}

Table 4. Earthquake source parameters for the Büsiin Gol earthquake from seismology.

\begin{tabular}{l|lll}
\hline Parameters & CMT & NEIC & NSDC \\
\hline Longitude $\left(^{\circ}\right)$ & 98.14 & 98.05 & 97.99 \\
Latitude $\left(^{\circ}\right)$ & 51.26 & 51.38 & 51.41 \\
Depth $(\mathrm{km})$ & 12 & 13 & 2 \\
Strike $\left(^{\circ}\right)$ & $194 / 56$ & - & - \\
Dip $\left(^{\circ}\right)$ & $46 / 52$ & - & - \\
Rake $\left(^{\circ}\right)$ & $-121 /-61$ & - & - \\
$M_{0}(\mathrm{~N} \mathrm{~m})$ & $4.91 \times 10^{16}$ & - & - \\
$M_{\mathrm{w}}$ & 5.1 & 5.1 & 4.86 \\
\hline
\end{tabular}

\section{Discussion}

We compared our InSAR estimates with three seismological solutions (CMT, NEIC and NSDC), although there are some inconsistencies between these catalogs.

Hatanbulag. For this composite event the seismic catalogs show a significant discrepancy. The InSAR-derived moment $M_{0}=3.83 \times 10^{17} \mathrm{~N} \mathrm{~m}\left(M_{\mathrm{w}} 5.65\right)$ is five and four times greater than the seismic moments of the CMT $\left(M_{0}=7.36 \times 10^{16} \mathrm{~N} \mathrm{~m}\right)$ and NEIC $\left(M_{0}=9.1 \times 10^{16}\right.$ $\mathrm{N} \mathrm{m}$ ) estimates, respectively, but the moment magnitude agrees well with the NSDC. The strike and dip agree well with the CMT estimate, while the rake and depth agree with the NEIC estimate. In general, the discrepancy in moments between InSAR and seismology may be caused by a number of factors, including contributions from pre- and post-seismic deformations, or assumptions about the elastic moduli used in the moment estimate. For our study, the HB co-seismic interferograms used for modeling incorporate the moderate magnitude $M_{\mathrm{w}} 5.0$ foreshock according to the CMT $\left(4.53 \times 10^{16}\right)$ and NEIC (moment is not reported) and also include the post-seismic deformation since they cover several months and years after the earthquake. However, the contribution of the foreshock may be small, because all three seismological catalogs locate the foreshock below 12 $\mathrm{km}$ depth, and the NEIC and NSDC locate the foreshock further away from the mainshock (NEIC in $\sim 20 \mathrm{~km}$ southeast, NSDC in $\sim 27 \mathrm{~km}$ northeast, Table 2 ). In addition, as inferred from the InSAR analysis, the NSDC catalog has a location uncertainty for the mainshock of about $30 \mathrm{~km}$ that its location occurred outside the InSAR frame, while the CMT and NEIC estimation agree well within about 4 and $6 \mathrm{~km}$, respectively. Adding the CMT reported moments for the fore- and mainshock yields a total seismic moment of $1.19 \times 10^{17} \mathrm{~N} \mathrm{~m}$. This is still three times lower than the InSAR estimated value.

Similar discrepancies were found for the Zagros earthquakes studied by Lohman and Simons (2005) and Nissen et al. (2010). To adequately constrain these events, it will be necessary to perform more sophisticated modeling that

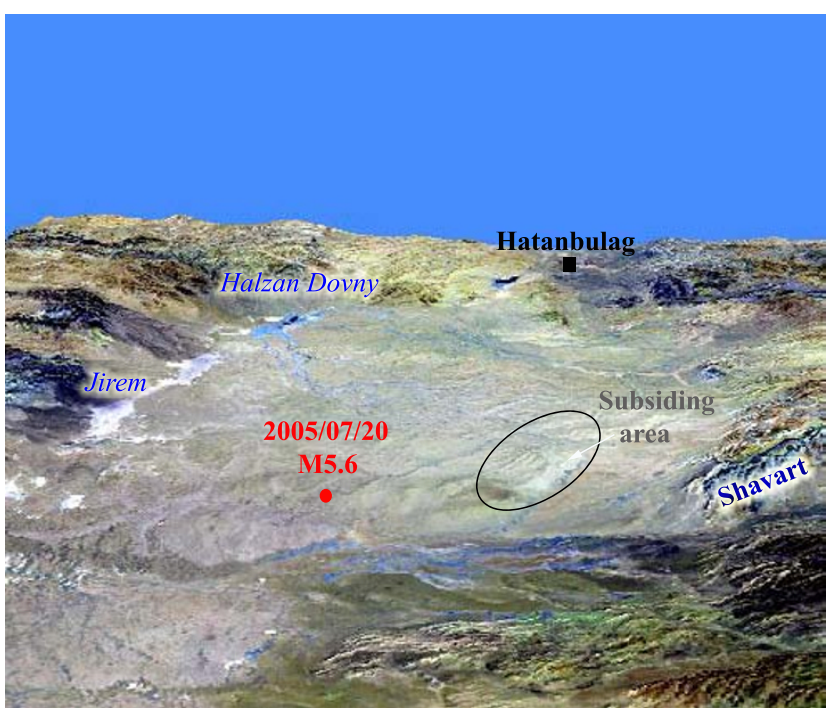

Fig. 9. 3D perspective view of the HB earthquake area from the south. SRTM DEM overlayed by LANDSAT ETM (RGB/754-wet area in blue), vertical exaggeration is 25 , scale is M1:100000.

includes both the seismic and InSAR data. This event is an example which demonstrates the limitation of InSAR in distinguishing multiple earthquakes which have occurred in the same place, or a nearby location, which adds uncertainties in the estimation of both the moment and the focal mechanism.

The observed questionable subsidence pattern presumably related to the local post-seismic process, hydrological effects or topography-correlated atmospheric effects. The latter assumption is most likely supported based on the examination of the Landsat ETM, relief (from the field visit) and radar amplitude images. The questionable pattern corresponds to the NE-SW trending small topographic high surrounded by dry streambeds, west of the Shavart range (Fig. 9).

Büsiin Gol. The InSAR estimate for this event agrees relatively well with three seismological estimates for all parameters with small uncertainties. The radar estimate of the epicentral location is closest to the NEIC estimated value within $4.4 \mathrm{~km}$, while the CMT catalog has an uncertainty of about $11 \mathrm{~km}$. The InSAR determined depth of $2.4 \mathrm{~km}$ agrees well with the NSDC estimated depth, while both CMT and NEIC place it deeper at 12 and $13 \mathrm{~km}$, respectively, which is not common for the Büsiin Gol area and may be less reliable for detection with InSAR. For this event, the difference between the InSAR-derived moment of $5.56 \times 10^{16} \mathrm{~N} \mathrm{~m}$ and the seismological estimate of $4.91 \times 10^{16} \mathrm{~N}$ m is relatively small. 


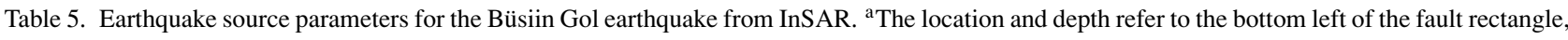
following the convention of Okada (1985).

\begin{tabular}{ccccccccccc}
\hline $\begin{array}{c}\text { Longitude } \\
\left({ }^{\circ}\right)\end{array}$ & $\begin{array}{c}\text { Latitude } \\
\left({ }^{\circ}\right)\end{array}$ & $\begin{array}{c}\text { Depth } \\
(\mathrm{km})\end{array}$ & $\begin{array}{c}\text { Strike } \\
\left({ }^{\circ}\right)\end{array}$ & $\begin{array}{c}\text { Dip } \\
\left({ }^{\circ}\right)\end{array}$ & $\begin{array}{c}\text { Rake } \\
\left({ }^{\circ}\right)\end{array}$ & $\begin{array}{c}\text { Length } \\
(\mathrm{km})\end{array}$ & $\begin{array}{c}\text { Width } \\
(\mathrm{km})\end{array}$ & $\begin{array}{c}\text { Slip } \\
(\mathrm{mm})\end{array}$ & $\begin{array}{c}\text { Moment } \\
(\mathrm{N} \mathrm{m})\end{array}$ & $\begin{array}{c}M_{\mathrm{w}} \\
5.04\end{array}$ \\
\hline 98.04 & 51.34 & 2.4 & 52 & 49 & -62 & 1.8 & 1.6 & 644 & $5.56 \times 10^{16}$ \\
\hline
\end{tabular}

\section{Conclusion}

We analysed the co-seismic deformation of two moderate-sized earthquakes which occurred in the stable southeastern and northwestern regions of Mongolia using ASAR descending and PALSAR ascending data, respectively. Both datasets were well suited for mapping displacements in the landscapes of the corresponding study sites. The ASAR data applied for the sparsely-vegetated desert region of the South East Gobi, confirmed its sensitivity to small-scale displacements, and revealed millimeter-scale deformations even over a period of three years. The complication here is that two moderate-sized earthquakes occurred at the same place within a few hours which cannot be distinguished by the InSAR. The capability of ALOS PALSAR interferometry to produce successful results for denselyvegetated areas that have been previously reported by many other authors (e.g., Aoki et al., 2008) was demonstrated in the Büsiin Gol area. The main limitation of the present study was the availability of SAR data acquired from one direction only. Therefore, in this study the InSAR data are sensitive to the location and depth but not very sensitive to the fault orientation. The two earthquakes both occurred in the upper few kilometers of the crust. The HB earthquake had a blind thrust mechanism with a small left-lateral component with a geodetic moment estimated to be $3.83 \times 10^{17}$ $\left(M_{\mathrm{w}} 5.65\right)$. The $\mathrm{BG}$ earthquake had a normal motion with a geodetic moment of $5.56 \times 10^{16}\left(M_{\mathrm{w}} 5.1\right)$. Our InSAR study of the HB earthquake reveals a minimum fault plane area of $\sim 30 \mathrm{~km}^{2}$ which could generate a $M_{\mathrm{w}}>5.6$ earthquake. This confirms the suggestion of Khilko et al. (1985) that this small area in the Hutag Uul craton belongs to a zone of potential seismicity of $4.5<M<7.0$. The revealed geometry of the fault indicates the SW-NE compressional tectonic regime of the area, which is consistent with the World Stress Map (Heidbach et al., 2008) and tectonic stresses reported by Barth and Wenzel (2010), and Xu (2001) in the adjacent region of NE China. The normal fault mechanism of the $M_{\mathrm{w}} 5.1 \mathrm{BG}$ earthquake confirms the determination of Radziminovitch et al. (2007) that, along with strike-slip faulting, normal faults are also common in this junction zone. The InSAR derived depth supports the suggestion that earthquakes in the HBG often occur in a shallow crust.

In general, this InSAR study of earthquakes in Mongolia has demonstrated that provided a sufficient amount of suitable interferometric data is available, the InSAR technique can complement the sparse seismic observations of the region and may complement future seismic event relocation efforts.

Acknowledgments. This work was supported by the Japan Society for the Promotion of Science. We are grateful to Kurt Feigl, Manabu Hashimoto and Takeshi Sagiya for their valuable comments to improve the paper.

\section{References}

Aki, K., Earthquake mechanism, Tectonophysics, 13, 423-446, 1972. Aoki, Y., M. Furuya, and T. Kato, Coseismic deformation due to the 2007 Chuetsu-oki earthquake (M6.8), Earth Planets Space, 60, 1075-1080, 2008.

Badarch, G., W. D. Cunningham, and B. F. Windley, A new terrane subdivision for Mongolia: implications for the Phanerozoic crustal growth of Central Asia, J. Asian Earth Sci., 21, 87-110, 2002.

Baljinnyam, I., A. Bayasgalan, B. A. Borisov, A. Cisternas, M. G. Dem'yanovich, L. Ganbaatar, V. M. Kochetkov, R. A. Kurushin, P. Molnar, H. Philip, and Yu. Ya. Vashchilov, Ruptures of major earthquakes and active deformation in Mongolia and its surroundings, Geol. Soc. Am. Memoir, 181, 1-58, 1993.

Barth, A. and F. Wenzel, New constraints on the intraplate stress field of the Amurian plate deduced from light earthquake focal mechanisms, Tectonophysics, 482, 160-169, 2010.

Dawson, J., P. Cummins, P. Tregoning, and M. Leonard, Shallow intraplate earthquakes in Western Australia observed by Interferometric Synthetic Aperture Radar, J. Geophys. Res., 113, B11408, doi:10.1029/2008JB005807, 2008.

Delouis, B., J. Déverchère, V. Melnikova, N. Radziminovich, L. Lonke, C. Laroqque, J. F. Ritz, and San'kov, A reappraisal of the 1950 (Mw6.9) Mondy earthquake, Siberia, and its relationship to the strain pattern at the south-western end of the Baikal rift zone, Terra Nova, 14, 491-500, 2002.

Dugarmaa, T., A. Schlupp et al., Seismic Hazard Assessment of Ulaanbaatar, capital of Mongolia. Seismic micro zoning map, Report to the Ulaanbaatar Administration, p.156, 2006.

Farr, T. G., P. A. Rosen, E. Caro, R. Crippen, R. Duren, S. Hensley, M. Kobrick, M. Paller, E. Rodriguez, L. Roth, D. Seal, S. Shaffer, J. Shimada, J. Umland, M. Werner, M. Oskin, D. Burbank, and D. Alsdorf, The Shuttle Radar Topography Mission, Rev. Geophys., 45, RG2004, 33 pp., 2007.

Feigl, K. L. and E. Dupré, RNGCHN: a program to calculate displacement components from dislocations in an elastic half-space with applications for modeling geodetic measurements of crustal deformation, Comput. Geosci., 25, 695-704, 1999.

Feigl, K. L., A. Sergent, and D. Jacq, Estimation of an earthquake focal mechanism from a satellite radar interferogram - application to the December 4, 1992 Landers aftershock, Geophys. Res. Lett., 22, 1037-1040, 1995.

Goldstein, R. M. and C. L. Werner, Radar interferogram filtering for geophysical applications, Geophys. Res. Lett., 25(21), 4035-4038, 1998.

Graham, S. A., M. S. Hendrix, C. L. Johnson, D. Badamgarav, G. Badarch, J. Amory, M. Porter, R. Barsbold, L. E. Webb, and B. R. Hacker, Sedimentary record and tectonic implications of Mesosoic rifting in southeast Mongolia, GSA Bull., 113(12), 1560-1579, 2001.

Hanks, T. C. and H. Kanamori, A moment magnitude scale, J. Geophys. Res., 84(B5), 2348-2350, 1979.

Heidbach, O., M. Tingay, A. Barth, J. Reinecker, D. Kurfess, and B. Müller, The World Stress Map database release 2008, doi:10.1594/GFZ.WSM.Rel2008, 2008.

Jónsson, S., H. Zebker, P. Segall, and F. Amelung, Fault slip distribution of the $1999 M_{w} 7.1$ Hector Mine, California, Earthquake, estimated from Satellite Radar and GPS measurements, Bull. Seismol. Soc. Am., 92(4), 1377-1389, 2002.

Johnson, C. L., Polyphase evolution of the East Gobi basin: sedimentary and structural records of Mesozoic-Cenozoic intraplate deformation in Mongolia, Basin Res., 16, 79-99, 2004.

Khilko, S. D., R. A. Kurushin, V. M. Kochetkov, L. A. Misharina, V. I. Melnikova, N. A. Gilyova, S. V. Lastochkin, I. Baljinnyam, and D. Monkhoo, Earthquakes and the bases of the seisminc zoning of Mongolia, Transactions, 41, in The joint Soviet-Mongolian scientific-research geological expedition, edited by N. S. Zaitsev et al., 222 pp, Nauka, Moscow, 1985.

Klyuchevskii, A. V., L. Selenge, V. M. Demjanovich, G. Bayar, V. I. Mel- 
nikova, N. A. Radziminovich, and M. Adyaa, Kinematics and dynamics of aftershocks of the 1991 Busiingol earthquake, in Complex geophysical and seismological investigations in Mongolia, edited by V. I. Dzhurik and T. Dugarmaa, 315 pp, Ulaanbaatar-Irkutsk, 2004.

Klyuchevskii, A. V., T. Dugarmaa, V. M. Demyanovich, and G. Bayart, Basic parameters and characteristics of seismicity in Mongolia. Proceedings of Conference commemorating the 50th anniversary of the 1957 Gobi-Altay earthquake, Ulaanbaatar, 2007.

Lamb, M. A., A. D. Hanson, S. A. Graham, G. Badarch, and L. E. Webb, Left-lateral sense offset of upper Proterozoic to Paleozoic features across the Gobi Onon, Tost, and Zuunbayan faults in southern Mongolia and implications for other Central Asian faults, Earth Planet. Sci. Lett., 173, 183-194, 1999.

Logachev, N. A., History and geodynamics of Baikal rift. J. Geol. Geophys., Russian Academy of Sciences, 44, 391-406, 2003 (in Russian).

Lohman, R. B. and M.Simons, Locations of selected small earthquakes in the Zagros Mountains, Geochem. Geophys. Geosyst., 6, 2005.

Massonet, D. and K. Feigl, Radar Interferometry and its application to changes in the Earth's surface, Rev. Geophys., 36, 441-500, 1998.

National Atlas of the Mongolian Peoples Republic, Ulaanbaatar\& Moskva, 1990.

Nissen, E., F. Yamini-Fard, M. Tatar, A. Gholamzadeh, E. Bergman, and J R. Elliott, The vertical separation of mainshock rupture and microseismicity at Qeshm island in the Zagros fold-and-thrust belt, Iran, Earth Planet. Sci. Lett., 296, 181-194, 2010.

Okada, Y., Surface deformation due to shear and tensile faults in a half space, Bull. Seismol. Soc. Am., 75, 1135-1154, 1985.

Peltzer, G., P. Rosen, F. Rogez, and K. Hudnut, Poroelastic rebound along the Landers 1992 earthquake surface rupture, J. Geophys. Res., 103(B12), 30,131-30,145, 1998.

Radziminovitch, N. A., V. I. Melnikova, M. Adyaa, D. Ankhtsetseg, L. Selenge, and G. Bayar, Recent stress and strain state of the crust of the northern Mongolia and southern Baikal regions from focal solutions, Proceedings of the conference commemorating the 50th anniversary of the 1957 Gobi-Altay earthquake, Ulaanbaatar, 25 July-08 August, 2007.

Scharroo, R. and P. N. A. M. Visser, Precise orbit determination and gravity field improvement for the ERS satellites, J. Geophys. Res., 103(C4),
8113-8127, 1998.

Sengör, A. M. C., B. A. Natalín, and V. S. Burtman, Evolution of the Altaid tectonic collage and Palaeozoic crustal growth in Eurasia, Nature, 364, 1993.

Strozzi, T., U. Wegmüller, Ch. Werner, and A. Wiesmann, Measurement of slow uniform surface displacement with $\mathrm{mm} / \mathrm{year}$ accuracy, IEEE Transactions on Geoscience and Remote Sensing, 2000.

Uflyand, A. K., A. V. Ilýin, and A. I. Spirkin, Basins of Baykalian type in Northern Mongolia. Translated from Vpadiny Baykalśkogo tipa Severnoy Mongolii, Byul. MOIP, otd. geol., 1969, XLIV, 5022, in Int. Geol. Rev., 12, 1980.

Webb, L. E. and C. L. Johnson, Tertiary strike-slip faulting in southeastern Mongolia and implications for Asian tectonics, Earth Planet. Sci. Lett., 241, 323-335, 2006.

Wegmüller, U. and Ch. Werner, GAMMA SAR Processor and interferometry software, Proceedings of the 3rd ERS Symposium, 1997.

Wright, T., B. Parsons, and E. Fieldings, Measurement of interseismicstrain accumulation across the North Anatolian Fault by satellite radar interferometry, Geophys. Res. Lett., 28, 2117-2120, 2001.

$\mathrm{Xu}, \mathrm{Z} . \mathrm{h}$., A present-day tectonic stress map for eastern Asia region, Acta Seismol. Sin., 14(5), 524-533, 2001.

Yue,Y. and J. G. Liou, Two-stage evolution model for the Altyn Tagh fault, China, Geology, 27, 227-230, 1999.

Zebker, H. A., P. A. Rosen, R. M. Goldstein, A. Gabriel, and Ch. L. Werner, On the derivation of coseismic displacement fields using differential radar interferometry: The Landers earthquake, J. Geophys. Res., 99, 19617-19634, 1994.

Zonenshain, L. P. and L. A. Savostin, Geodynamics of the Baikal rift zone and plate tectonics of Asia, Tectonophysics, 76, 1-45, 1981.

Zorin, Yu. A., Geodynamics of the western part of the Mongolia-Okhotsk collisional belt, Trans-Baikal region (Russia) and Mongolia, Tectonophysics, 306, 33-56, 1999.

Sh. Amarjargal (e-mail: amarshrgl@yahoo.com), T. Kato, and M. Furuya 